\title{
ANALISIS PEMASARAN PISANG NANGKA
}

\section{MARKETING ANALYSIS OF BANANAS "NANGKA"}

\author{
Riska Fitriani Nuramalia ${ }^{1^{*}}, \mathrm{Hj}$. Rina Nuryati ${ }^{2}$, Suyudi $^{3}$ \\ ${ }^{1}$ Jurusan Agribisnis, Fakultas Pertanian, Universitas Siliwangi, JI. Siliwangi No. 24 Tasikmalaya \\ ${ }^{2,3}$ Dosen Fakultas Pertanian, Universitas Siliwangi, JI. Siliwangi No. 24 Tasikmalaya \\ *E-mail corresponding: riskafn2998@gmail.com
}

\begin{abstract}
ABSTRAK
Penelitian ini bertujuan untuk mengetahui saluran pemasaran, biaya, keuntungan, margin pemasaran, farmer's share dan efisiensi pemasaran pada pemasaran pisang nangka. Metode penelitian menggunakan survei. Teknik pengambilan sample yang digunakan adalah snowball sampling. Tempat penelitian di Desa Ciampanan Kecamatan Cineam Kabupaten Tasikmalaya dilakukan pada bulan Juni hingga September 2020. Hasil penelitian menunjukkan : terdapat 3 saluran pemasaran pisang nangka, yaitu : saluran pemasaran I : petani - pedagang pengumpul - pedagang besar desa - konsumen antara, saluran pemasaran II : petani - pedagang pengumpul - pedagang besar luar desa - pedagang pengecer - konsumen akhir, saluran pemasaran III : petani - pedagang pengumpul - pedagang besar desa - pedagang besar luar desa - pedagang pengecer - konsumen akhir. Biaya pemasaran tertinggi terdapat pada saluran pemasaran III sebesar Rp 2.114,8/kg sedangkan biaya pemasaran terendah terdapat pada saluran pemasaran I sebesar Rp 1.117,9/kg. Keuntungan pemasaran tertinggi terdapat pada saluran pemasaran III sebesar Rp 2.885,2/kg sedangkan keuntungan pemasaran terendah terdapat pada saluran pemasaran I sebesar Rp 682,1/kg. Berdasarkan analisis margin pemasaran dan farmer's share saluran yang efisien adalah saluran pemasaran I dengan nilai margin pemasaran sebesar 18,2 persen dan nilai farmer's share sebesar 52,6 persen. Berdasarkan analisis efisiensi pemasaran saluran I,II dan III sudah efisien, namun saluran yang paling efisien adalah saluran pemasaran I dengan nilai efisiensi pemasaran sebesar 29,4 persen.
\end{abstract}

Kata kunci: saluran pemasaran, efisiensi pemasaran, pisang nangka

\section{ABSTRACT}

This study aims to determine the marketing channels, marketing costs and profits, marketing margins, farmer's share and marketing eficiency bananas "nangka". The research method used the survey. The sampling technique used snowball sampling. The research site is in Ciampanan Village, Cineam District, Tasikmalaya Regency in Juni-September 2020. This study indicate: there are 3 marketing channels for bananas "nangka", namely: marketing channel l: farmer - collector trader - village wholesaler - intermediate consumer, marketing channel II: farmer - a trader wholesaler outside the village - retailer - consumesr, marketing channel III: farmers - collecting traders - village wholesalers - outside the village wholesalers - retailers - consumers. The highest marketing cost was found in marketing channel III amounting to $R p 2,114.8 / \mathrm{kg}$ while the lowest marketing cost was found in marketing channel I amounting to Rp 1,117.9 / kg. The highest marketing profit was found in marketing channel III of Rp. $2,885.2$ / kg, while the lowest marketing profit was found in marketing channel I of Rp. 682.1 / kg. Based on the analysis of marketing margin and farmer's share, the efficient channel is marketing channel I with a marketing margin of 18.2 percent and a farmer's share value of 52.6 percent. Based on the analysis of marketing efficiency channels I, II, and III are efficient, but the most efficient channel is marketing channel I with a marketing efficiency value of 29.4 percent.

Keywords: marketing channels, marketing efficiency, bananas "nangka" 


\section{PENDAHULUAN}

Sektor pertanian merupakan sektor yang strategis dalam pembangunan nasional. Pengembangan pertanian saat ini masih mempunyai peranan dalam pengembangan ekonomi, terutama kontribusinya terhadap tanaman pangan, kesempatan kerja dan lapangan usaha. Peran sektor pertanian dalam memacu perekonomian dapat dilihat lebih luas lagi dari mendistribusikan hasil-hasil pembangunan kepada masyarakat (Rozalina dan Akbar,2016).

Pembangunan subsektor pertanian tanaman hortikultura merupakan salah satu bagian yang penting dari pembangunan pertanian. Salah satu komoditas tanaman hortikultura yang banyak digemari oleh masyarakat adalah pisang (Direktorat Jenderal Bina Produksi Hortikultura, 2009). Pengembangan komoditas pisang bertujuan memenuhi kebutuhan akan konsumsi buah-buahan seiring dengan bertambahnya jumlah penduduk dan meningkatanya kesadaran masyarakat akan pentingnya gizi yang Tabel 1. Produksi Buah Pisang Menurut Kabupaten/Kota (Ton) di Provinsi Jawa Barat Tahun 2019

\begin{tabular}{lcc}
\hline \multicolumn{1}{c}{ Kabupaten } & $\begin{array}{c}\text { Produksi Buah Pisang } \\
\text { (Ton) }\end{array}$ & Persentase (\%) \\
\hline 1. Cianjur & $192.605,9$ & 17,1 \\
2. Tasikmalaya & $128.095,7$ & 11,4 \\
3. Purwakarta & $110.382,1$ & 9,8 \\
4. Garut & $110.360,4$ & 9,8 \\
5. Sukabumi & $109.756,4$ & 9,7 \\
\hline \multicolumn{2}{l}{ Sumber: BPS Provinsi Jawa Barat dalam Angka 2020 }
\end{tabular}

dimana pisang merupakan sumber vitamin, mineral dan juga karbohidrat (Ambarita,2015).

Pisang (Musa paradisiaca L.) merupakan tanaman buah-buahan tropika yang berasal dari Asia Tenggara, Brazil dan India. Di Asia Tenggara pisang diyakini berasal dari Semenanjung Malaysia dan Filipina. Pisang telah lama berkembang di India yaitu sejak 500 tahun sebelum Masehi dan menyebar sampai ke daerah Pasifik (Satuhu dan Supryadi, 2000). Buah pisang menjadi komoditas buah tropis yang disukai di dunia, hal ini dikarenakan rasanya yang lezat, gizinya yang tinggi dan harganya relatif murah dan mudah didapat.

Berdasarkan data Badan Pusat Statistik, Produksi pisang terbesar di Jawa Barat tersebar di beberapa Kabupaten/Kota antara lain Kabupaten Cianjur, Kabupaten Garut, Kabupaten Tasikmalaya, Kabupaten Sukabumi dan Kabupaten Purwakarta. Hal tersebut dapat dilihat pada Tabel 1 . 
Berdasarkan data Badan Pusat Statistik Kabupaten Tasikmalaya daerah penghasil pisang terbesar di Kabupaten Tasikmalaya tersebar di beberapa kecamatan salah satunya yaitu Kecamatan Cineam dengan produksi pisang pada Tahun 2018 sebesar 6.941,1 ton $(5,4 \%)$. Salah satu desa yang memiliki potensi produksi pisang paling tinggi di Kecamatan Cineam adalah Desa Ciampanan. Berdasarkan data dari petani di Desa Ciampanan Kecamatan Cineam Kabupaten Tasikmalaya salah satu jenis pisang yang menjadi unggulan dan mempunyai produksi tinggi adalah pisang nangka.

Produksi pisang nangka yang semakin meningkat setiap tahunnya memberikan peluang yang sangat besar untuk memasarkan pisang tersebut. Pisang nangka sangatlah popular dengan rasanya yang manis, sedikit sepat, sedikit asam dan memiliki aroma yang harus hampir menyerupai aroma nangka. Pisang nangka cenderung di konsumsi dengan diolah terlebih dahulu sehingga meningkatkan permintaan akan buah pisang nangka tersebut. Harga pisang nangka juga relative murah berkisar $\mathrm{Rp}$ 4000,- hingga Rp 7.000,- per kilogram. Harga yang murah ini juga menjadi alasan pisang nangka digemari sebagai bahan baku olahan pisang.

Menurut Meliati (2002), pemasaran merupakan proses akhir dari kegiatan usahatani dimana produsen menyampaikan hasil produksi kepada konsumen. System pemasaran memiliki peran yang sangat penting dalam mendistribusikan komoditas-komoditas pertanian dari pusat produksi ke pusat konsumsi. Dalam proses pemasaran hasil pertanian perlu adanya lembaga-lembaga perantara yang menghubungkan antara sentra produksi dan sentra konsumsi dengan melakukan berbagai aktivitas yang memberikan nilai guna bagi produk yang dipasarkan.

Menurut Agustina (2008), beberapa permasalahan dalam pemasaran komoditas hortikultura secara umum yang dihadapi oleh pelaku pemasaran adalah tingginya biaya pemasaran dan pembagian balas jasa yang adil bersifat asimetris, bahkan balas jasa tersebut atas fungsi pemasaran lebih besar mengelompok pada pedagang besar, sementara petani, pedagang pengumpul dan pedagang pengecer bagiannya kecil. Dengan demikian, sebaran margin pemasaran cenderung tidak merata atau tidak efisien dan lebih mengelompok pada pedagang besar atau bandar, supplier, dan sebagainya. Mahalnya biaya pemasaran komoditas hortikultura merupakan akibat dari ketidakefisienan yang disebabkan oleh panjangnya saluran pemasaran.

Menurut Mubyarto (1995) dalam

Baladina, Anindita, dan Putri (2011), 
pemasaran yang efisien harus memenuhi dua syarat, yaitu mampu menyampaikan hasil-hasil dari petani produsen ke konsumen dengan biaya serendahrendahnya dan mampu mengadakan pembagian yang adil secara keseluruhan harga yang harus dibayarkan kepada konsumen akhir dan kepada semua pihak yang ikut serta dalam kegiatan pemasaran tersebut. Dalam hal ini, dilakukan penelitian untuk menganalisis bagaimana saluran pemasaran pisang nangka, berapa besarnya biaya, keuntungan, margin pemasaran, farmer's share, dan efisiensi pemasaran pisang nangka dari Desa Ciampanan Kecamatan Cineam Kabupaten Tasikmalaya.

\section{METODE PENELITIAN}

Penelitian dilakukan di Desa Ciampanan Kecamatan Cineam Kabupaten Tasikmalaya mulai bulai Juni hingga September 2020. Pemilihan daerah penelitian ini dilakukan secara sengaja (purposive) dengan pertimbangan bahwa Desa Ciampanan Kecamatan Cineam Kabupaten Tasikmalaya merupakan salah satu daerah penghasil pisang nangka yang potensial. Metode yang digunakan dalan penelitian ini adalah survey. Menurut Singarimbun (2006) survey yaitu cara mengumpulkan data penelitian dengan mengambil sejumlah sampel dari suatu populasi dan menggunakan kuisioner yang memuat daftar pertanyaan sebagai alat pengumpulan data yang pokok. Tujuan dari metode survey adalah untuk mendapatkan gambaran yang mewakili suatu daerah. Data yang dikumpulkan berupa data primer dan data sekunder. Data primer dilakukan dengan melakukan wawancara langsung kepada responden dengan menggunakan daftar pertanyaan (kuisioner) yang telah disiapkan. Data Sekunder ialah data yang diperoleh dari instansi dan dinas yang terkait dengan penelitian ini.

Responden merupakan orang yang dijadikan sumber data dalam suatu penelitian. Penentuan responden lembaga pemasaran dalam penelitian ini dilakukan dengan menggunakan metode snowball sampling. Snowball sampling yaitu teknik penentuan sample yang mula-mula jumlahnya kecil kemudian membesar. Dengan mengikuti alur pemasaran dengan menjadikan sampel yang pertama sebagai penentu sampel berikutnya. Penentuan sampel ditentukan atas dasar informasi dari sampel sebelumnya (Sugiyono, 2017). Metode snowball sampling yang dilakukan dalam penelitian ini dengan mengikuti alur saluran pemasaran dari lembaga perantara hingga konsumen akhir. Dalam penentuan sampel, pada saat survey delakukan dengan cara mencari informasi dari seorang pedagang pengumpul sampai kepada lembaga pemasaran 


\begin{abstract}
berikutnya yang terlibat dalam pemasaran pisang nangka. Jumlah responden untuk setiap lembaga pemasaran adalah 4 orang pedagang pengumpul, 2 orang pedagang besar desa, 2 orang pedagang besar luar desa dan 3 orang pedagang pengecer.
\end{abstract}

\section{Kerangka Analisis}

Saluran pemasaran dalam
penelitian ini dianalisis dengan menggunakan metode deskriptif. Metode Deskriptif adalah metode yang menjelaskan, merinci, atau menggambarkan objek yang diteliti.

Biaya dan keuntungan pemasaran dihitung berdasarkan rumus menurut Saefuddin (1985), sebagai berikut:

a) Biaya Pemasaran

$$
B p=B p 1+B p 2+\cdots+B p n
$$

Keterangan :

Bp : Biaya Pemasaran (Rp/kg)

Bp1+Bp2+ ...Bpn : Biaya Pemasaran tiaptiap lembaga pemasaran $(\mathrm{Rp} / \mathrm{kg})$

b) Keuntungan pemasaran

$$
\pi=H_{j}-\left(H_{B}+B T\right)
$$

Keterangan :

$$
\begin{array}{ll}
\pi & \text { : Keuntungan Pemasaran }(\mathrm{Rp} / \mathrm{kg}) \\
\mathrm{Hj} & : \text { Harga jual }(\mathrm{Rp} / \mathrm{Kg}) \\
\mathrm{HB} & : \text { Harga beli }(\mathrm{Rp} / \mathrm{Kg}) \\
\mathrm{BT} & \text { : Biaya Pemasaran }
\end{array}
$$$$
\text { Margin pemasaran dihitung }
$$
berdasarkan rumus menurut Sudiyono (2004), sebagai berikut:

$$
M P=P_{r}-P_{f}
$$

Keterangan:

MP : Margin Pemasaran (Rp/kg)

$\operatorname{Pr}$ : Harga jual di tingkat konsumen/harga eceran $(\mathrm{Rp} / \mathrm{kg})$

Pf : Harga beli di tingkat produsen ( $\mathrm{Rp} / \mathrm{kg})$ Bagian biaya untuk setiap lembaga pemasaran dihitung dengan rumus:

$$
S b i=\frac{B i}{P r-P f} \times 100 \%
$$

Keterangan :

$\mathrm{SBi}$ : bagian biaya setiap lembaga pemasaran ke-I (\%)

$\mathrm{Bi}$ : biaya yang dikeluarkan setiap lembaga pemasaran $\mathrm{ke}-\mathrm{I}(\mathrm{Rp} / \mathrm{kg})$

Pr: harga beli di tingkat konsumen (Rp/kg)

Pf : harga jual di tingkat petani $(R p / k g)$

Keuntungan dari setiap lembaga pemasaran dihitung dengan rumus :

$$
S k i=\frac{K i}{P r-P f} \times 100 \%
$$

Keterangan :

Ski : bagian keuntungan setiap lembaga tataniaga ke-I (\%)

$\mathrm{Ki}$ : keuntungan yang diperoleh setiap lembaga tataniaga ke-l (Rp/kg)

Pr: harga beli di tingkat konsumen ( $\mathrm{Rp} / \mathrm{kg})$

$\mathrm{Pf}$ : harga jual di tingkat petani ( $\mathrm{Rp} / \mathrm{kg})$

Farmer's share dihitung berdasarkan rumus menurut Kohl dan Uhl (2002), sebagai berikut:

$$
F s=\frac{P f}{P r} x 100 \%
$$


Keterangan :

Fs : Bagian yang diterima petani (\%)

Pf : Harga jual di tingkat petani (Rp/kg)

$\operatorname{Pr}$ : Harga beli di tingkat konsumen $(\mathrm{Rp} / \mathrm{kg})$

Efisiensi pemasaran dihitung berdasarkan rumus menurut Soekartawi (2002), sebagai berikut:

$$
E P=\frac{T B}{T N P} \times 100 \%
$$

Keterangan:

EP : Efisiensi Pemasaran (\%)

TB : Total Biaya Pemasaran (Rp/kg)

TNP : Total Nilai Produk (Rp/kg)

Kaidah keputusan pada efisiensi pemasaran ini adalah:

EP sebesar 0-50\%, maka saluran pemasaran sudah dikatakan efisien.

EP $>50 \%$, maka saluran pemasaran dikatakan kurang efisien.

\section{HASIL DAN PEMBAHASAN}

\section{Saluran Pemasaran Pisang Nangka}

Saluran pemasaran diartikan sebagai pihak-pihak yang terlibat dalam aktivitas bisnis atau usaha dalam mendistribusikan dan menyampaikan produk ataupun jasa mulai dari petani hingga konsumen akhir (Kohl dan Uhl, 2002). Proses pemasaran pisang nangka bisa didasari berdasarkan adanya hubungan antara produsen dengan tiap lembaga pemasaran yang meliputi hubungan kemitraan dan kekeluargaan.

Berdasarkan hasil pada saat penelitian, diketahui terdapat tiga saluran pemasaran pisang nangka dari Desa Ciampanan Kecamatan Cinema Kabupaten Tasikmalaya.

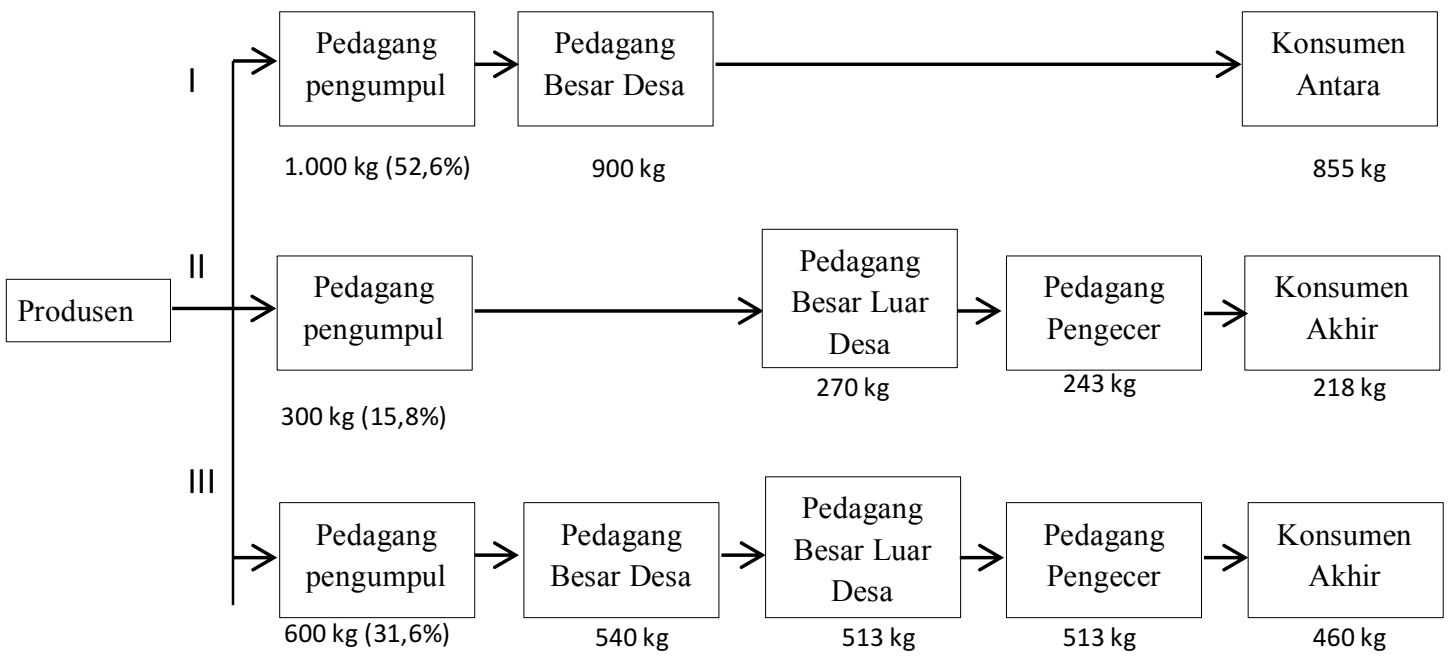

Gambar 1. Saluran Pemasaran Pisang Nangka

Saluran Pemasaran I merupakan

1) Saluran Pemasaran I : Petani Pedagang pengumpul - Pedagang Besar Desa - Konsumen Antara saluran dua tingkat karena dalam proses pemasarannya terdapat dua lembaga pemasaran yang terlibat yaitu pedagang 
pengumpul dan pedagang besar desa. Dalam saluran dua tingkat ini distribusi pengaliran pisang nangka dimulai dari petani yang menjual pisang nangka dengan harga jual Rp 2.000,- per kilogram ke pedagang pengumpul yang berada di desa tersebut atau pedagang pengumpul tersebut membeli pisang nangka dengan secara langsung ke kebun untuk panen sendiri atas permintaan petani. Pedagang Pengumpul menjual pisang nangka kepada pedagang besar yang ada di Desa Ciampanan dengan harga jual Rp 2.800,- per kilogram. Pedagang besar menjual kembali pisang nangka secara langsung kepada konsumen antara yaitu pabrik keripik Naluri Jaya dengan harga jual Rp 3.800,- per kilogram.

2) Saluran Pemasaran II : Petani Pedagang Pengumpul- Pedagang Besar Luar Desa - Pedagang Pengecer Konsumen akhir

Saluran Pemasaran II merupakan saluran tiga tingkat karena dalam proses pemasarannya terdapat tiga lembaga pemasaran yang terlibat yaitu pedagang pengumpul, pedagang besar luar desa dan pedagang pengecer. Dalam saluran tiga tingkat ini distribusi pengaliran pisang nangka dimulai dari petani yang menjual pisang nangka dengan harga jual Rp 1.900,- per kilogram ke pedagang pengumpul yang berada di desa tersebut atau pedagang pengumpul tersebut membeli pisang nangka dengan secara langsung ke kebun untuk panen sendiri atas permintaan petani. Pedagang Pengumpul menjual pisang nangka kepada pedagang besar luar desa yaitu dari Manonjaya dengan harga jual Rp 2.500,- per kilogram. Pedagang besar luar desa tersebut menjual kembali pisang nangka kepada pedagang pengecer yang ada di pasar rel dengan harga Rp 3.300,- per kilogram. Kemudian Pedagang pengecer menjual kembali pisang nangka kepada konsumen akhir dengan harga jual Rp 5.000,- per kilogram.

3) Saluran Pemasaran III : Petani Pedagang pengumpul - Pedagang Besar Desa - Pedagang Besar Luar Desa Pedagang Pengecer - Konsumen akhir

Saluran Pemasaran III merupakan saluran empat tingkat karena dalam proses pemasarannya terdapat empat lembaga pemasaran yang terlibat yaitu pedagang pengumpul, pedagang besar desa, pedagang besar luar desa dan Pedagang pengecer. Dalam saluran empat tingkat ini distribusi pengaliran pisang nangka dimulai dari petani yang menjual pisang nangka dengan harga jual Rp 2.000,- per kilogram ke pedagang pengumpul yang berada di desa tersebut atau pedagang pengumpul tersebut membeli pisang nangka dengan secara langsung ke kebun untuk panen sendiri atas permintaan petani. Pedagang pengumpul menjual pisang nangka 
kepada pedagang besar desa pada saat hari pasaran yaitu hari selasa dan hari jum'at dengan harga jual Rp 3.000,- per kilogram. Pedagang besar desa menjual pisang nangka kepada pedagang besar luar desa yaitu dari Rajapolah dengan harga jual $\operatorname{Rp} 3.500$,- per kilogram. Pedagang besar tersebut menjual kembali pisang nangka kepada pedagang pengecer yang ada di pasar Rajapolah dengan harga Rp 4.000,- per kilogram. Kemudian Pedagang pengecer menjual kembali pisang nangka kepada konsumen akhir dengan harga jual Rp 7.000,- per kilogram.

\section{Biaya, Keuntungan dan Margin Pemasaran}

Biaya pemasaran menurut Soekartawi (1993), adalah biaya yang dikeluarkan untuk keperluan pemasaran. Pergerakan barang atau jasa dari produsen ke konsumen tentunya memerlukan suatu biaya, biaya tersebut berupa biaya transportasi, biaya retribusi, biaya penyusutan, dan lainnya. Dengan adanya biaya pemasaran yang dikeluarkan tentunya akan meningkatkan harga jual terhadap barang atau jasa. Dengan demikian setiap lembaga pemasaran akan meningkatkan harga barang atau jasa dengan harapan mendapatkan suatu keuntungan dari kegiatan pemasaran. Keuntungan pemasaran adalah selisih harga jual dan harga beli dikurangi dengan biaya pemasaran.

Menurut Limbong dan Sitorus (1987), margin pemasaran dapat didefinisikan sebagai perbedaan harga yang dibayar konsumen dengan harga yang diterima produsen. Besarnya margin pemasaran pada setiap saluran pemasaran akan berbeda, karena hal ini dipengaruhi oleh panjang pendeknya saluran pemasaran dan aktivitas-aktivitas yang telah dilaksanakan serta keuntungan yang diharapkan oleh setiap lembaga pemasaran yang terlibat dalam pemasaran. Untuk mengetahui besarnya biaya, keuntungan dan margin pemasaran dalam pemasaran pisang nangka pada Saluran Pemasaran I dapat dilihat pada Tabel 2.

Berdasarkan Tabel 2 dapat diketahui bahwa dalam saluran pemasaran I lembaga pemasaran yang terlibat adalah pedagang pengumpul dan pedagang besar desa. Margin pemasaran pemasaran yang diperoleh sebesar $\mathrm{Rp}$ $1.800,-/ k g$, margin pemasaran ini didistribusikan ke biaya-biaya dan keuntungan lembaga pemasaran. Total biaya pemasaran sebesar $\operatorname{Rp} 1.117,9 / \mathrm{kg}$ $(62,1 \%)$ dan total keuntungan pemasaran sebesar $\operatorname{Rp} 662,1 / \mathrm{kg}(37,9 \%)$. 
Tabel 2. Rata-rata Biaya, Keuntungan dan Margin Pemasaran Pisang Nangka pada Saluran Pemasaran I

\begin{tabular}{|c|c|c|c|c|}
\hline \multirow{2}{*}{ No } & \multirow{2}{*}{ Uraian } & \multirow{2}{*}{ Nilai (Rp/kg) } & \multicolumn{2}{|c|}{ Distribusi Margin (\%) } \\
\hline & & & Sbi & Ski \\
\hline \multirow[t]{10}{*}{1} & Pedagang Pengumpul & & & \\
\hline & a. Volume Pembelian $(\mathrm{Kg})$ & $1.000,0$ & & \\
\hline & b. Volume Penjualan $(\mathrm{Kg})$ & 900,0 & & \\
\hline & c. Harga Beli (Rp) & $2.000,0$ & & \\
\hline & d. Harga Jual (Rp) & $2.800,0$ & & \\
\hline & Biaya Transportasi (Rp) & 150,0 & 8,3 & \\
\hline & Biaya Tenaga Kerja (Rp) & 150,0 & 8,3 & \\
\hline & Biaya Penyusutan (Rp) & 280,0 & 15,5 & \\
\hline & e. Total Biaya Pemasaran & 580,0 & & \\
\hline & f. Keuntungan Pemasaran & 220,0 & & 12,2 \\
\hline \multirow[t]{14}{*}{2} & Pedagang Besar Desa & & & \\
\hline & a. Volume Pembelian $(\mathrm{Kg})$ & 900,0 & & \\
\hline & b. Volume Penjualan (Kg) & 855,0 & & \\
\hline & c. Harga Beli (Rp) & $2.800,0$ & & \\
\hline & d. Harga Jual (Rp) & $3.800,0$ & & \\
\hline & Biaya Transportasi (Rp) & 166,7 & 9,3 & \\
\hline & Biaya Tenaga Kerja (Rp) & 166,7 & 9,3 & \\
\hline & Biaya Penyimpanan (Rp) & 2,1 & 0,1 & \\
\hline & Biaya Retribusi (Rp) & 5,5 & 0,3 & \\
\hline & Biaya Kebersihan (Rp) & 5,5 & 0,3 & \\
\hline & Biaya Listrik (Rp) & 1,4 & 0,1 & \\
\hline & Biaya Penyusutan (Rp) & 190 & 10,6 & \\
\hline & e. Total Biaya Pemasaran & 537,9 & & \\
\hline & f. Keuntungan Pemasaran & 462,1 & & 25,7 \\
\hline \multicolumn{2}{|c|}{ Total Margin Pemasaran } & $1.800,0$ & 62,1 & 37,9 \\
\hline
\end{tabular}

Sumber: Data primer diolah 2020

Volume pembelian yang dilakukan pedagang pengumpul sebanyak $1.000 \mathrm{~kg}$ dengan harga beli $\mathrm{Rp} 2.000,-/ \mathrm{kg}$. Pedagang pengumpul mengeluarkan biaya-biaya seperti biaya transportasi, biaya tenaga kerja dan biaya penyusutan. Biaya transportasi yang dikeluarkan yaitu sebesar Rp 150,-/kg (8,3 \%). Biasanya pedagang pengumpul menggunakan motor milik pribadi untuk mengangkut pisang nangka. Biaya transportasi yang dikeluarkan dipengaruhi dengan banyaknya pisang nangka yang diangkut dari kebun pisang sampai ke tempat penyimpanan pedagang pengumpul yang nantinya akan dibawa oleh pedagang besar.
Biaya tenaga kerja adalah biaya yang dikeluarkan sebagai akibat pemanfaatan tenaga kerja yang memuat pisang nangka dari kebun sampai ke tempat penyimpanan pedagang pengumpul. Jumlah tenaga kerja yang dibutuhkan yaitu dua HKO. Biaya tenaga kerja sebesar Rp 150,-/kg (8,3 \%). Biaya penyusutan dikeluarkan akibat berkurangnya volume pisang nangka dengan pembuangan tangkai pisang nangka sebesar Rp 280,-/kg (15,5\%). Dalam satu kali penjualan pedagang pengumpul rata-rata menjual sebanyak 900 kg dengan harga jual Rp 2.800,-/kg.

Volume pembelian pedagang besar sebanyak $900 \mathrm{~kg}$ dengan harga beli $\mathrm{Rp}$ 2.800,-/kg. Pedagang besar 
mengeluarkan biaya-biaya seperti biaya transportasi, biaya tenaga kerja, biaya penyimpanan, biaya listrik, biaya retribusi dan biaya penyusutan. Biaya transportasi yang dikeluarkan yaitu sebesar Rp 166,7/kg (9,3\%). Biasanya pedagang besar menggunakan mobil pick up pribadi untuk mengangkut pisang nangka baik pembelian ke pedagang pengumpul maupun penjualan ke konsumen antara yaitu pabrik keripik Naluri Jaya. Biaya transportasi yang dikeluarkan dipengaruhi dengan banyaknya pisang nangka yang diangkut. Biaya tenaga kerja adalah biaya yang dikeluarkan pedagang besar untuk membayar tenaga kerja yang bertugas dalam pengangkutan dan penimbangan. Jumlah tenaga kerja yang dibutuhkan dalam kegiatan pemasaran pisang nangka tersebut adalah dua HKO. Besarnya biaya tenaga kerja yang dikeluarkan adalah $\operatorname{Rp} 166,7 / \mathrm{kg}(9,3 \%)$.

Biaya penyimpanan adalah biaya yang dikeluarkan untuk kepentingan sehari-hari dalam penyimpanan atau persediaan pisang nangka yang nantinya akan diantar ke konsumen antara yaitu pabrik keripik Naluri Jaya. Besarnya biaya yang dikeluarkan adalah $\operatorname{Rp} 2,1 / \mathrm{kg}(0,1$ \%). Biaya listrik dikeluarkan untuk kepentingan sehari-hari yang memerlukan penerangan pada waktunya. Besarnya biaya listrik adalah Rp 1,4/kg $(0,08 \%)$. Biaya kebersihan yaitu biaya yang dikeluarkan sebagai suatu kewajiban kepada petugas kebersihan di tempat penyimpanan pisang nangka yang telah bersedia membersihkan daerah penyimpanan. Besarnya biaya kebersihan adalah $\operatorname{Rp} 5,5 / \mathrm{kg}$ (0,3\%). Biaya retribusi yaitu biaya yang dikeluarkan selama perjalanan per sekali angkut. Biaya retribusi ini seperti pungutan tak resmi selama perjalanan ke pabrik keripik. Besarnya biaya retribusi adalah sebesar Rp 5,5/kg (0,3 \%). Biaya penyusutan yaitu sebesar Rp 190,-/kg $(10,6 \%)$, pada satu kali penjualan pedagang besar rata-rata menjual sebanyak $855 \mathrm{~kg}$ dengan harga jual Rp $3.800,-/ \mathrm{kg}$.

Berdasarkan Tabel 3 dapat diketahui bahwa dalam saluran pemasaran II, lembaga pemasaran yang terlibat adalah pedagang pengumpul, pedagang besar luar desa dan pedagang pengecer. Margin pemasaran pemasaran yang diperoleh sebesar Rp 3.100,-/kg , margin pemasaran ini didistribusikan ke biaya-biaya dan keuntungan lembaga pemasaran. Total biaya pemasaran sebesar Rp 1.772,4/kg (57,2 \%) dan total keuntungan pemasaran sebesar $R p$ $1.327,6 / \mathrm{kg}(42,8 \%)$.

Volume pembelian yang dilakukan pedagang pengumpul sebanyak $300 \mathrm{~kg}$ dengan harga beli Rp 1.900,-/kg. Pedagang pengumpul mengeluarkan biaya-biaya seperti biaya transportasi, biaya tenaga kerja, biaya penyimpanan 
dan biaya penyusutan. Biaya transportasi yang dikeluarkan sebesar Rp 150,-/kg $(4,8 \%)$. Biasanya pedagang pengumpul menggunakan motor milik pribadi untuk mengangkut pisang nangka. Biaya transportasi yang dikeluarkan dipengaruhi dengan banyaknya pisang nangka yang diangkut dari kebun pisang sampai ke tempat penyimpanan yang nantinya akan dibawa oleh pedagang besar.

Tabel 3. Rata-rata Biaya, Keuntungan dan Margin Pemasaran Pisang Nangka pada Saluran Pemasaran II

\begin{tabular}{|c|c|c|c|c|}
\hline \multirow{2}{*}{ No } & \multirow{2}{*}{ Uraian } & \multirow{2}{*}{ Nilai (Rp/kg) } & \multicolumn{2}{|c|}{ Distribusi Margin (\%) } \\
\hline & & & Sbi & Ski \\
\hline \multirow[t]{11}{*}{1} & Pedagang Pengumpul & & & \\
\hline & a. Volume Pembelian $(\mathrm{Kg})$ & 300,0 & & \\
\hline & b. Volume Penjualan (Kg) & 270,0 & & \\
\hline & c. Harga Beli (Rp) & $1.900,0$ & & \\
\hline & d. Harga Jual (Rp) & $2.500,0$ & & \\
\hline & Biaya Transportasi (Rp) & 150,0 & 4,8 & \\
\hline & Biaya Tenaga Kerja (Rp) & 100,0 & 3,2 & \\
\hline & Biaya Penyimpanan (Rp) & 3,3 & 0,1 & \\
\hline & Biaya Penyusutan (Rp) & 250,0 & 8,1 & \\
\hline & e. Total Biaya Pemasaran & 503,3 & & \\
\hline & f. Keuntungan Pemasaran & 96,7 & & 3,1 \\
\hline \multirow[t]{11}{*}{2} & Pedagang Besar Luar Desa & & & \\
\hline & a. Volume Pembelian $(\mathrm{Kg})$ & 270,0 & & \\
\hline & b. Volume Penjualan (Kg) & 243,0 & & \\
\hline & c. Harga Beli (Rp) & $2.500,0$ & & \\
\hline & d. Harga Jual (Rp) & $3.300,0$ & & \\
\hline & Biaya Transportasi (Rp) & 83,3 & 2,7 & \\
\hline & Biaya Tenaga Kerja (Rp) & 116,7 & 3,8 & \\
\hline & Biaya Retribusi (Rp) & 16,7 & 0,5 & \\
\hline & Biaya Penyusutan (Rp) & 320,0 & 10,3 & \\
\hline & e. Total Biaya Pemasaran & 536,7 & & \\
\hline & f. Keuntungan Pemasaran & 263,3 & & 8,5 \\
\hline \multirow[t]{13}{*}{3} & Pedagang Pengecer & & & \\
\hline & a. Volume Pembelian $(\mathrm{Kg})$ & 243,0 & & \\
\hline & b. Volume Penjualan (Kg) & 218,0 & & \\
\hline & c. Harga Beli (Rp) & $3.300,0$ & & \\
\hline & d. Harga Jual (Rp) & $5.000,0$ & & \\
\hline & Biaya Tenaga Kerja (Rp) & 164,6 & 5,3 & \\
\hline & Biaya Bongkar (Rp) & 41,2 & 1,3 & \\
\hline & Biaya Listrik (Rp) & 0,6 & 0,02 & \\
\hline & Biaya Kebersihan (Rp) & 3,3 & 0,1 & \\
\hline & Biaya Penyimpanan (Rp) & 8,3 & 0,3 & \\
\hline & Biaya Penyusutan (Rp) & 514,4 & 16,6 & \\
\hline & e. Total Biaya Pemasaran & 732,4 & & \\
\hline & f. Keuntungan Pemasaran & 967,6 & & 31,2 \\
\hline \multicolumn{2}{|c|}{ Margin Pemasaran } & $3.100,0$ & 57,2 & 42,8 \\
\hline
\end{tabular}

Sumber: Data primer diolah 2020

Besarnya biaya penyimpanan adalah sebesar $\operatorname{Rp} 3,3 / \mathrm{kg}(0,1 \%)$. Biaya penyusutan adalah biaya yang
Biaya tenaga kerja adalah biaya yang dikeluarkan sebagai akibat pemanfaatan tenaga kerja dalam melakukan proses pemasaran pisang. Tenaga kerja disini memuat pisang nangka dari kebun sampai ke tempat penyimpanan pedagang pengumpul. Jumlah tenaga kerja yang dibutuhkan yaitu satu HKO. Besarnya biaya tenaga kerja sebesar Rp 100,-/kg (3,2 \%). 
pedagang pengumpul rata-rata menjual sebanyak $270 \mathrm{~kg}$ dengan harga jual Rp $2.500,-/ \mathrm{kg}$.

Volume pembelian pedagang besar luar desa sebanyak $270 \mathrm{~kg}$ dengan harga beli Rp 2.500,-/kg. Pedagang besar luar desa mengeluarkan biaya-biaya seperti biaya transportasi, biaya tenaga kerja, biaya retribusi dan biaya penyusutan. Biaya transportasi yang dikeluarkan yaitu sebesar Rp 83,3/kg (2,7 \%). Biasanya pedagang besar menggunakan mobil pick up pribadi untuk mengangkut pisang nangka baik pembelian ke pedagang pengumpul maupun penjualan. Biaya transportasi yang dikeluarkan dipengaruhi dengan banyaknya pisang nangka yang diangkut.

Biaya tenaga kerja adalah biaya yang dikeluarkan pedagang besar untuk membayar tenaga kerja yang bertugas dalam pengangkutan dan penimbangan. Jumlah tenaga kerja yang dibutuhkan dalam kegiatan pemasaran pisang nangka tersebut adalah satu HKO. Besarnya biaya tenaga kerja Rp 116,7/kg $(3,8 \%)$. Biaya retribusi yaitu biaya yang dikeluarkan selama perjalanan per sekali angkut. Biaya retribusi ini seperti parkir dan pungutan tidak resmi selama perjalanan. Besarnya biaya retribusi adalah sebesar Rp 16,7/kg (0,5\%). Besarnya biaya penyusutan yaitu sebesar Rp 320,-/kg (10,3 \%), pada satu kali penjualan pedagang pengumpul luar desa rata-rata menjual sebanyak $243 \mathrm{~kg}$ dengan harga jual Rp 3.300,-/kg.

Volume pembelian pedagang pengecer sebanyak $243 \mathrm{~kg}$ dengan harga beli Rp 3.300,-/kg. Pedagang pengecer mengeluarkan biaya-biaya seperti biaya tenaga kerja, biaya bongkar, biaya listrik, biaya kebersihan, biaya penyimpanan dan biaya penyusutan. Biaya tenaga kerja adalah biaya yang dikeluarkan pedagang pengecer untuk membayar tenaga kerja yang bertugas dalam pengangkutan, penimbangan dan melayani pembeli. Jumlah tenaga kerja yang dibutuhkan dalam kegiatan pemasaran pisang nangka tersebut adalah satu HKO. Besarnya biaya untuk tenaga kerja Rp $164,6 / k g(5,3 \%)$.

Biaya bongkar adalah biaya yang dikeluarkan untuk membayar tenaga kerja yang hanya bongkar muat pisang nangka. Besarnya biaya bongkar adalah sebesar Rp 41,2/kg (1,3\%). Biaya listrik adalah biaya yang dikeluarkan untuk kepentingan sehari-hari yang memerlukan penerangan. Besarnya biaya listrik adalah sebesar Rp 0,6/kg $(0,02 \%)$. Biaya kebersihan yaitu biaya yang dikeluarkan sebagai suatu kewajiban kepada petugas kebersihan yang telah bersedia membersihkan daerah tempat penjualan. Besarnya biaya sampah adalah sebesar $\operatorname{Rp} 3,3 / \mathrm{kg}(0,1$ $\%)$. Biaya penyimpanan yang dikeluarkan akibat proses pematangan pisang nangka 


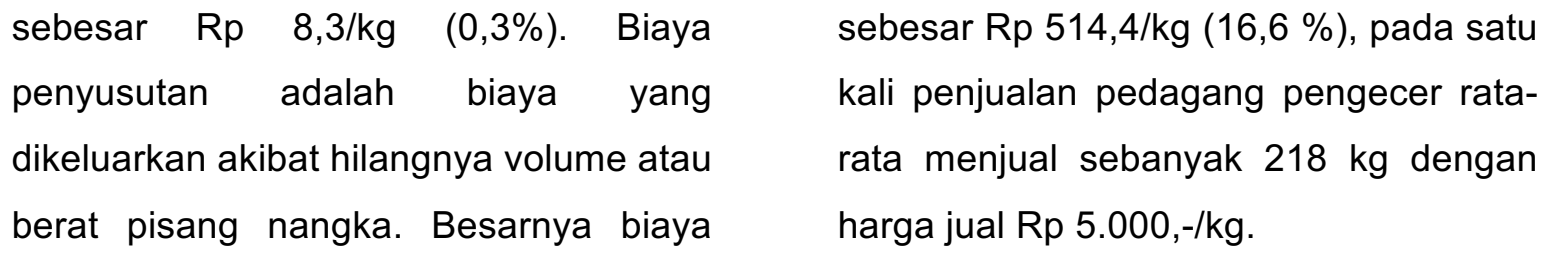
penyusutan yang dikeluarkan yaitu

Tabel 4. Rata-rata Biaya, Keuntungan dan Margin Pemasaran Pisang Nangka pada Saluran Pemasaran III

\begin{tabular}{|c|c|c|c|c|}
\hline \multirow{2}{*}{ No } & \multirow{2}{*}{ Uraian } & \multirow{2}{*}{ Nilai (Rp/kg) } & \multicolumn{2}{|c|}{ Distribusi Margin (\%) } \\
\hline & & & Sbi & Ski \\
\hline \multirow[t]{10}{*}{1} & Pedagang Pengumpul & & & \\
\hline & a. Volume Pembelian $(\mathrm{Kg})$ & 600,0 & & \\
\hline & b. Volume Penjualan $(\mathrm{Kg})$ & 540,0 & & \\
\hline & c. Harga Beli (Rp) & $2.000,0$ & & \\
\hline & d. Harga Jual (Rp) & $3.000,0$ & & \\
\hline & Biaya Transportasi (Rp) & 166,7 & 3,3 & \\
\hline & Biaya Tenaga Kerja(Rp) & 100,0 & 2,0 & \\
\hline & Biaya Penyusutan (Rp) & 300,0 & 6,0 & \\
\hline & e. Total Biaya Pemasaran & 566,7 & & \\
\hline & f. Keuntungan Pemasaran & 433,3 & & 8,7 \\
\hline \multirow[t]{11}{*}{2} & Pedagang Besar Desa & & & \\
\hline & a. Volume Pembelian $(\mathrm{Kg})$ & 540,0 & & \\
\hline & b. Volume Penjualan (Kg) & 513,0 & & \\
\hline & c. Harga Beli (Rp) & $3.000,0$ & & \\
\hline & d. Harga Jual (Rp) & $3.500,0$ & & \\
\hline & Biaya Timbangan (Rp) & 55,5 & 1,1 & \\
\hline & Biaya Muat bongkar (Rp) & 64,8 & 1,3 & \\
\hline & Biaya Penyimpanan (Rp) & 41,7 & 0,8 & \\
\hline & Biaya Penyusutan (Rp) & 175,0 & 3,5 & \\
\hline & e. Total Biaya Pemasaran & 337,0 & & \\
\hline & f. Keuntungan Pemasaran & 163,0 & & 3,3 \\
\hline \multirow[t]{10}{*}{3} & Pedagang Besar Luar Desa & & & \\
\hline & a. Volume Pembelian (Kg) & 513,0 & & \\
\hline & b. Volume Penjualan $(\mathrm{Kg})$ & 513,0 & & \\
\hline & c. Harga Beli (Rp) & $3.500,0$ & & \\
\hline & d. Harga Jual (Rp) & $4.000,0$ & & \\
\hline & Biaya Transportasi (Rp) & 200,0 & 4,0 & \\
\hline & Biaya Tenaga Kerja (Rp) & 185,2 & 3,7 & \\
\hline & Biaya Retribusi (Rp) & 5,0 & 0,1 & \\
\hline & e. Total Biaya Pemasaran & 390,2 & & \\
\hline & f. Keuntungan Pemasaran & 109,8 & & 2,2 \\
\hline \multirow[t]{12}{*}{3} & Pedagang Pengecer I dan II & & & \\
\hline & a. Volume Pembelian $(\mathrm{Kg})$ & 513,0 & & \\
\hline & b. Volume Penjualan (Kg) & 460,0 & & \\
\hline & c. Harga Beli (Rp) & $4.000,0$ & & \\
\hline & d. Harga Jual (Rp) & $7.000,0$ & & \\
\hline & Biaya Tenaga Kerja (Rp) & 66,8 & 1,3 & \\
\hline & Biaya Listrik(Rp) & 0,6 & 0,01 & \\
\hline & Biaya Penyimpanan (Rp) & 27,0 & 0,5 & \\
\hline & Biaya Kebersihan (Rp) & 3,3 & 0,07 & \\
\hline & Biaya Penyusutan (Rp) & 723,2 & 14,5 & \\
\hline & e. Total Biaya Pemasaran & 820,9 & & \\
\hline & f. Keuntungan Pemasaran & $2.179,1$ & & 43,6 \\
\hline \multicolumn{2}{|c|}{ Margin Pemasaran } & $5.000,0$ & 42,2 & 57,8 \\
\hline
\end{tabular}

pemasaran III lembaga pemasaran yang

Berdasarkan Tabel 4 dapat terlibat adalah pedagang pengumpul, diketahui bahwa dalam saluran pedagang besar desa, pedagang besar 
luar desa dan pedagang pengecer. Margin pemasaran pemasaran yang diperoleh sebesar Rp 5.000,-/kg, margin pemasaran ini didistribusikan ke biayabiaya dan keuntungan lembaga pemasaran. Total biaya pemasaran sebesar Rp 2.114,8/kg (42,2 \%) dan total keuntungan pemasaran sebesar $R p$ $2.885,2 / \mathrm{kg}(57,8 \%)$.

Volume pembelian yang dilakukan pedagang pengumpul sebanyak $600 \mathrm{~kg}$ dengan harga beli Rp 2.000,-/kg. Pedagang pengumpul mengeluarkan biaya-biaya seperti biaya transportasi, biaya tenaga kerja dan biaya penyusutan. Biaya transportasi yang dikeluarkan sebesar Rp 166,7/kg (3,3 \%). Biasanya pedagang pengumpul menggunakan motor milik pribadi untuk mengangkut pisang nangka. Biaya transportasi ini dipengaruhi dengan banyaknya pisang nangka yang diangkut dari kebun pisang sampai ke tempat penyimpanan pedagang pengumpul dan penjualan ke pedagang besar desa di pasar cineam.

Biaya tenaga kerja adalah biaya yang dikeluarkan sebagai akibat pemanfaatan tenaga kerja dalam melakukan proses pemasaran pisang. Tenaga kerja disini memuat pisang nangka dari kebun sampai ke los tempat penyimpanan pedagang pengumpul. Jumlah tenaga kerja yang dibutuhkan yaitu dua HKO. Besarnya biaya tenaga kerja yang dikeluarkan pedagang pengumpul sebesar Rp 100,-/kg (2\%). Besarnya biaya penyusutan yaitu sebesar Rp 300,-/kg (6 \%), pada satu kali penjualan pedagang pengumpul rata-rata menjual sebanyak $540 \mathrm{~kg}$ dengan harga jual Rp 3.000,-/kg.

Volume pembelian pedagang besar desa sebanyak $540 \mathrm{~kg}$ dengan harga beli Rp 3.000,-/kg. Pedagang besar mengeluarkan biaya-biaya seperti biaya timbangan, biaya muat bongkar, biaya penyimpanan dan biaya penyusutan. Biaya timbangan adalah biaya yang dikeluarkan pedagang besar untuk membayar tenaga kerja yang bertugas dalam penimbangan. Jumlah tenaga kerja penimbangan yang dibutuhkan dalam kegiatan pemasaran pisang nangka tersebut adalah dua HKO. Besarnya biaya tenaga kerja adalah $\mathrm{Rp}$ $55,5 / \mathrm{kg}$ (1,1 \%). Biaya muat bongkar adalah biaya yang dikeluarkan pedagang besar untuk membayar tanaga kerja yang bertugas dalam pengangutan. Jumlah tenaga kerja yang dibutuhkan adalah satu HKO. Besarnya biaya untuk muat bongkar adalah $\operatorname{Rp~64,8/kg~(1,3~\% ).~}$

Biaya penyimpanan adalah biaya yang dikeluarkan untuk penyimpanan sementara pisang nangka dan sekaligus tempat penjualan. Besarnya penyimpanan adalah $\operatorname{Rp} 41,7 / \mathrm{kg}$ (0,8 \%). Biaya penyusutan yang dikeluarkan yaitu sebesar Rp 175,-/kg (3,5\%), pada satu kali penjualan pedagang besar rata-rata 
menjual sebanyak $513 \mathrm{~kg}$ dengan harga jual Rp 3.500,-/kg.

Volume pembelian pedagang besar luar desa sebanyak $513 \mathrm{~kg}$ dengan harga beli Rp 3.500,-/kg. Pedagang besar luar desa mengeluarkan biaya-biaya seperti biaya transportasi, biaya tenaga kerja dan biaya retribusi. Biaya transportasi yang dikeluarkan yaitu sebesar Rp 200,-/kg (4 $\%)$. Biasanya pedagang besar luar desa menggunakan mobil pick up pribadi untuk mengangkut pisang nangka baik pembelian ke pedagang besar desa maupun penjualan ke konsumen akhir. Biaya transportasi yang dikeluarkan dipengaruhi dengan banyaknya pisang nangka yang diangkut. Biaya tenaga kerja adalah biaya yang dikeluarkan pedagang besar luar desa untuk membayar tenaga kerja yang bertugas dalam pengangkutan dan penimbangan. Jumlah tenaga kerja yang dibutuhkan adalah dua HKO. Besarnya biaya tenaga kerja Rp 185,2/kg $(3,7 \%)$.

Biaya retribusi yaitu biaya yang dikeluarkan selama perjalanan per sekali angkut. Biaya retribusi ini seperti parkir dan pungutan tidak resmi selama perjalanan. Besarnya biaya retribusi adalah sebesar Rp 5,-/kg. Pada satu kali penjualan pedagang pengumpul rata-rata menjual sebanyak $513 \mathrm{~kg}$ dengan harga jual Rp 4.000,-/kg.

Volume pembelian pedagang pengecer sebanyak $513 \mathrm{~kg}$ dengan harga beli Rp 4.000,-/kg. Pedagang pengecer mengeluarkan biaya-biaya seperti biaya tenaga kerja, biaya listrik, biaya penyimpanan, biaya kebersihan, dan biaya penyusutan. Biaya tenaga kerja adalah biaya yang dikeluarkan pedagang pengecer untuk membayar tenaga kerja yang bertugas dalam pengangkutan, penimbangan dan melayani pembeli. Jumlah tenaga kerja yang dibutuhkan adalah empat HKO. Besarnya biaya untuk tenaga kerja $\operatorname{Rp~66,8/kg~(1,3~\% ).~}$

Besarnya biaya listrik yang dikeluarkan adalah $\mathrm{Rp} 0,6 / \mathrm{kg}(0,01 \%)$. Biaya kebersihan yaitu biaya yang dikeluarkan sebagai suatu kewajiban kepada petugas kebersihan yang telah bersedia membersihkan daerah tempat penjualan. Besarnya biaya kebersihan adalah sebesar $\operatorname{Rp~3,3/kg~(0,07~5\% ).~}$ Biaya penyusutan yaitu sebesar Rp $723,2 / \mathrm{kg}(14,5 \%)$, pada satu kali penjualan pedagang pengecer rata-rata menjual sebanyak $460 \mathrm{~kg}$ dengan harga jual $\operatorname{Rp} 7.000,-/ \mathrm{kg}$.

$$
\text { Berdasarkan nilai margin }
$$
pemasaran pada tiap saluran pemasaran, saluran I merupakan saluran yang efisien dengan nilai margin sebesar 18,2 persen. Namun keuntungan pemasaran lebih kecil dibandingkan dengan biaya pemasaran, hal ini dikarenakan banyaknya aktivitas yang dilakukan oleh lembaga pemasaran. Sedangkan saluran III merupakan saluran yang tidak efisien 
dengan nilai margin sebesar 50,5 persen, hal ini dikarenakan banyaknya lembaga pemasaran yang terlibat dalam saluran pemasaran. Namun keuntungan pemasaran yang diterima lebih tinggi dibandingkan dengan biaya pemasaran, hal ini dikarenakan tingginya harga jual yang dilakukan pedagang pengecer dengan tujuan untuk mengantisipasi risiko yang akan ditanggung pada saat proses pemasaran pisang nangka.

Hasil penelitian ini bertolak belakang dengan hasil penelitian yang dilakukan oleh Agustina (2008) sebelumnya, yang menyatakan bahwa balas jasa atas fungsi pemasaran lebih besar mengelompok pada pedagang besar, sementara petani, pedagang pengumpul dan pedagang pengecer bagiannya kecil. Dengan demikian, sebaran margin pemasaran cenderung tidak merata atau tidak efisien dan lebih Tabel 5. Farmer's Share pada Saluran Pemasaran I,II dan III

\begin{tabular}{ccrrr}
\hline No & Saluran Pemasaran & $\begin{array}{c}\text { Rata-rata Harga } \\
\text { Jual di Tingkat } \\
\text { Petani (Rp/kg) }\end{array}$ & $\begin{array}{c}\text { Rata-rata Harga } \\
\text { Beli di Tingkat } \\
\text { Konsumen } \\
(\text { Rp/kg) }\end{array}$ & Farmer's Share (\%) \\
\hline 1 & I & 2.000 & 3.800 & 52,6 \\
2 & II & 1.900 & 5.000 & 38,0 \\
3 & III & 2.000 & 7.000 & 28,6 \\
\hline
\end{tabular}

Sumber: Data primer diolah 2020

Berdasarkan Tabel 13 dapat diketahui bahwa saluran pemasaran I dapat dikatakan lebih efisien dari saluran lainnya karena bagian harga yang diterima oleh petani sebesar 52,6 persen lebih besar dibanding dengan saluran II mengelompok pada pedagang besar. Namun dalam penelitian ini balas jasa yang diterima cenderung lebih besar mengelompok pada pedagang pengecer baik pada saluran pemasaran II dan III. Hal ini dikarenakan pedagang pengecer menjual pisang nangka dengan harga tinggi untuk mengantisipasi risiko yang akan ditanggung pada saat memasarkan pisang nangka.

\section{Farmer's Share}

Menurut Kohl dan Uhl (2002) Farmer's Share dapat didefinisikan sebagai bagian dari harga yang diterima petani terhadap harga yang dibayar oleh konsumen dalam suatu pemasaran dan dinyatakan dalam bentuk persen. Semakin tinggi nilai persentase farmer's share maka suatu system pemasaran dikatakan semakin efisien. Untuk lebih jelasnya dapat dilihat pada Tabel 5 . sebesar 38 persen dan saluran III sebesar 28,6 persen. Hal ini dikarenakan lembaga pemasaran yang terlibat sedikit sehingga salurannya lebih pendek dan keuntungan yang diterima petani lebih besar, sehingga menguntungkan bagi petani. Farmer's share mempunyai hubungan 
terbalik dengan margin pemasaran, hal ini terbukti pada saluran pemasaran I yang memiliki nilai margin lebih kecil dibandingkan dengan saluran lainnya.

\section{Efisiensi Pemasaran}

Menurut Soekartawi (1997), efisiensi pemasaran yang efisien adalah jika biaya pemasaran lebih rendah dibandingkan dengan nilai produk yang dipasarkan, maka semakin efisien dalam melaksanakan pemasaran. Untuk lebih jelasnya tingkat efisiensi saluran pemasaran pisang nangka dapat dilihat pada Tabel 6.

Tabel 6. Efisiensi Pemasaran pada Saluran Pemasaran I,II dan III

\begin{tabular}{ccrrr}
\hline No & Saluran Pemasaran & $\begin{array}{c}\text { Total Nilai Produk } \\
(\mathrm{Rp} / \mathrm{kg})\end{array}$ & $\begin{array}{c}\text { Biaya } \\
\text { Pemasaran } \\
(\mathrm{Rp} / \mathrm{kg})\end{array}$ & $\begin{array}{c}\text { Efisiensi } \\
\text { Pemasaran (\%) }\end{array}$ \\
\hline 1 & I & 3.800 & $1.117,9$ & 29,4 \\
2 & II & 5.000 & $1.772,4$ & 35,4 \\
3 & III & 7.000 & $2.114,8$ & 30,2 \\
\hline \multicolumn{2}{r}{ Sumber: Data primer diolah 2020 } & &
\end{tabular}

\section{Berdasarkan Tabel 6 dapat} diketahui bahwa nilai efisiensi pemasaran pada saluran pemasaran I yaitu sebesar 29,4 persen, disusul oleh saluran pemasaran III yaitu sebesar 30,2 persen dan yang terakhir saluran pemasaran tingkat II yaitu sebesar 35,4 persen. Secara keseluruhan pemasaran pisang nangka yang dipasarkan melalui tiga saluran pemasaran ini telah efisien. Hal ini sesuai dengan kaidah keputusan menurut Soekartawi (2002) yang menyatakan jika nilai efisiensi pemasaran antara $0-50$ persen maka saluran pemasaran tersebut dikatakan sudah efisien. Namun dalam setiap tingkatan tentunya ada saluran pemasaran yang paling efisien, yaitu saluran pemasaran I dikarenakan pada saluran ini biaya yang dikeluarkan oleh lembaga pemasaran yang terlibat merupakan biaya paling kecil dan harga beli di tingkat konsumen rendah, sehingga sangat menguntungkan bagi konsumen. 


\section{KESIMPULAN DAN SARAN}

\section{Kesimpulan}

Berdasarkan hasil penelitian dan pembahasan dapat disimpulkan bahwa:

1. Pemasaran Pisang nangka dari

Desa Ciampanan Kecamatan Cineam Kabupaten Tasikmalaya mempunyai tiga saluran pemasaran, yaitu:

a. Saluran Pemasaran I : Petani Pedagang Pengumpul - Pedagang Besar Desa - Konsumen Antara

b. Saluran Pemasaran II : Petani Pedagang Pengumpul - Pedagang Besar Luar Desa - Pedagang Pengecer - Konsumen Akhir

c. Saluran Pemasaran III : Petani Pedagang Pengumpul - Pedagang Besar Desa - Pedagang Besar Luar Desa - Pedagang Pengecer Konsumen Akhir

2. Biaya pemasaran tertinggi terdapat pada saluran pemasaran III sebesar Rp 2.114,8/kg sedangkan biaya pemasaran terendah terdapat pada saluran pemasaran I sebesar Rp $1.117,9 / \mathrm{kg}$. Keuntungan pemasaran tertinggi terdapat pada saluran pemasaran III sebesar Rp 2.885,2/kg sedangkan keuntungan pemasaran terendah terdapat pada saluran pemasaran I sebesar Rp 682,1/kg. Berdasarkan analisis margin pemasaran dan farmer's share saluran yang efisien adalah saluran pemasaran I dengan nilai margin pemasaran sebesar 18,2 persen dan nilai farmer's share sebesar 52,6 persen.

3. Berdasarkan analisis efisiensi pemasaran saluran I,II dan III sudah efisien, namun saluran yang paling efisien adalah saluran pemasaran I dengan nilai efisiensi pemasaran sebesar 29,4 persen.

\section{Saran}

Berdasarkan hasil penelitian, maka disarankan diperlukan adanya upaya untuk meningkatkan posisi tawar menawar antara lembaga pemasaran yang terlibat pada saluran pemasaran dalam penentuan harga. Selain itu lembaga pemasaran yang terlibat dalam memasarkan pisang nangka ini harus aktif dalam mencari informasi pasar mengenai harga maupun pesaing, sehingga dapat memudahkan proses pemasaran yang dilakukan.

\section{DAFTAR PUSTAKA}

Agustina, Adang. 2008. Pola Industri Komoditas Kentang. Kabupaten Bandung, Jawa barat. Jurnal Ekonomi Pembangunan. Vol, 9, No. 1, hal. 96-106.

Ambarita. 2015. Identifikasi Karakter Morfologis Pisang (Musa sp.) di Kabupaten Deli Serdang. Jurnal Agroterknologi Vol 4 No. 1. Program Studi Agroteknologi Fakultas Pertanian Universitas Sumatra Utara. Medan

Baladina, N. Anindita, R. Ariani, R. P. 2011. Analisis Efisiensi pemasaran durian di Desa Wonoagung, Kecamatan 
Kasembon, Kabupaten Malang. [Jurnal]. Habitat. 22 (1): 1-11.

BPS. 2020. Kabupaten Tasikmalaya dalam Angka 2019.

Kohls dan Uhl. 2002. Marketing of Agricultural Products. Yogyakarta: Universitas Gajah Mada.

Limbong, W.H. dan Sitorus,P. 1987. Pengantar Tataniaga Pertanian. Diklat, Jurusan IImu-IImu Sosial Ekonomi Pertanian. IPB. Bogor.

Meliati, N. 2002. Kelembagaan Pemasaran Pertanian : Permasalahan, Tantangan dan Alternatif Solusinya. Jakarta: Usese.

Rozalina dan Akbar,A. 2016. Analisis Pemasaran Pisang (Musa paradisiaca L.). [Jurnal].

Fakultas Pertanian. Universitas Samudra.

Saefuddin. 1985. Tataniaga Pertanian. Departemen Sosek, IPB. Bogor.

Singarimbun, M dan Efendi, S. 2006. Metode Penelitian Survei. Jakarta: LP3ES.

Soekartawi, 1997. Analisis Fungsi Produksi. Jakarta: Rajawali Pers. PT. Raja Grafindo Persada.

Soekartawi, 2002. Prinsip Dasar Manajemen Pemasaran HasilHasil Pertanian. Jakarta: PT. Raja Grafindo Persada.

Sudiyono, A. 2004. Pemasaran Pertanian. Malang: Universitas Muhammadiyah Malang.

Sugiyono. 2017. Metode Penelitian Kuantitatif, Kualitatif dan R\&D. Bandung: Alfabeta, CV. 